\title{
Book review: Global Portuguese - Linguistic Ideologies in Late Modernity by Luiz Moita-Lopes
}

$\mathrm{T}$ his book has ten articles that emphasize the power of Portuguese language spoken in four continents: Africa, Asia, America and Europe. Apart from these ten articles, the book has an introduction and end with an afterword.

The introduction written by MoitaLopes defends that linguistic ideologies have important roll in construction of actual Portuguese and he argues that "in today's postcolonial world, it is no longer possible to continue to use theoretical frameworks and analytical tools in the study of Portuguese which are typical of colonial modernity. The contemporary world has been reshaped by globalization processes which have deeply affected and diversified our lives in cultural, social, economic and political terms, configuring what Vertovec (2007) has called superdiversity" (p. 10). This idea of linguistic ideology flows in almost all articles of this book and sometimes it is analysed together with aspects of language policy and globalization.

Making a quick reading of each article I can see that:

Oliveira discusses the Portuguese language in the twentyfirst century based on three interesting dimensions: the internationalization of Portuguese, the internationalization of the management of Portuguese and the internationalization of Portuguesespeaking institutions through the language. So if I focus my attention in one of these dimensions, for instance, the first one, it shows the power of Portuguese in the world. Oliveira affirms that nowadays Portuguese is the official language in 10 countries, where 8 of them are members of the Community of Portuguese Language Countries (CPLP), and the other 2 are Equatorial Guinea and the Special Autonomous Region of Macau, China. 221 to 245 million people speak this language as a first or second language in four continents: America, Africa, Europe and Asia.

Giving the fact that Portuguese is an international strong language, Oliveira mentions that this language is officially recognized by 26 international organizations. There is a lot of language variation among the Portuguese speakers in the world. There are many reasons for it; for instance, Oliveira says, "within CPLP, Portuguese cohabits with approximately 339 different languages, which are bound up with local cultures (...)” (p. 29). Oliveira brings on this article a recent history of the geopolitics of the countries where Portuguese has official status. The referred history was analysed during the period from 1930 to 2012 and it had three phases and all of them where dominated by political ideologies concerned with colonization and decolonization, the long transition which came 
after decolonization and expansion and globalization of international relations with improved positioning of countries in which Portuguese is an official language.

Globalization as a determinant factor of chance is evident in some articles of this book, for instance, in the Signorini's article. According to Signorini, the main objective of his article is to present and discuss some relevant aspects of the ongoing debate in the field of language studies regarding the relationship between politics, linguistic policy and globalization. In this article aspects related with linguistic market, linguistic hegemony and orthographic agreement are clearly discussed.

Moita-Lopes's article deals with some effects of globalization, for instance, he mention the terms Portenglish (Portuguese and English) and Sportenglish (Spanish, Portuguese and English) as new tendencies to show the dynamism behind the multilingualism in a globalized era where the language contacts develop language mixture that can be understood as some possible ways of index identities. In this sense this article leaves opened the idea of "a new sociolinguistics of mobility offers critical epistemic, ethical and political gains for our times" (p. 100).

Fabrício's article based on the pragmatics of entextualization explore the idea of lusophony and the language of aggression and conflict from pragmatic perspective, focusing on heated and fierce exchanges between lusophone interlocutors (Brazilians and Portuguese) interacting on a critical website which encourages public debate. Her information came from two sources the Carta Capital website and Focus Magazine. The article shows that the entextualization processes are guided by ideologies and sometimes the ideologies behind the semiotic practices are so strong that problematize the idea of fraternity between Brazil and Portugal.

Pinto's article on this book is based on Portuguese spoken in Brazil. She discusses the question of fallacy of prefigured speaker identity and she argues "speaker identity prefiguration is a result of overlooked assumptions in sociolinguistic descriptions of Brazilian Portuguese" (p. 107). Aspects of language varieties and dialects are discussed on this article and Pinto shows that there is an ideology which emphasizes that educated speakers are linguistically better than speakers of popular varieties because educated speakers can adapt to any communicative situation while the speakers of popular varieties are not able to change the varieties or dialects that are most familiar to them. The formation of Brazilian Portuguese is something also discussed on this article and it mentioned that indigenous and African languages by one side and European Portuguese by other side have influence in the development of Brazilian Portuguese.

Silva's article entitled Sociolinguistic tension in the Portuguese/Lusophone community of Toronto, Canada, argues that "language, as well as other social constructs such as identity and 'community', are sets of symbolic and material resources that reveal and define social positionings and social structures in the context of a "market'” (p. 124). Starting from this perspective, Silva discusses the sociolinguistic tension existent in Canada between different speakers of Portuguese. There are speakers of standard Portuguese, and speakers of non-standard Portuguese (Azorean/ Brazilian and Portinglês $=$ a mixture of Portuguese and English). According to Silva (p. 128) the sociolinguistic context of Toronto's Portuguese market reveals 
how ideologies of language, identity, nationalism and class (among others) have served to marginalize Azoreans in Canada and, historically, in Portugal. Because of this marginalization of Azoreans in Canada, Silva concludes that many Azoreans and young Portuguese Canadians turn to silence, rather than being criticized for the way they speak, and they also turn away from traditional Portuguese spaces that insist on (re) producing a monolingual, monocultural and conservative market.

Migrations, multilingualism and language policies in Portugal and the United Kingdom - A polycentric approach is a title of an article present in this book written by Keating, Solovana and Barradas. These actors use their context of action and research (Portugal and the United Kingdom) to examine, through ethnographic perspectives, the use of Portuguese and the ways in which the values associated with European Portuguese are being negotiated in these two geopolitical contexts. Their study shows that there is a strong political will from part of Portugal to spray the use of Portuguese in United Kingdom and in other parts of the world. This is done through some normative documents that give support to promotion of Portuguese language education for residents abroad such as the Law-Decree 165/2006 and 165-C/2009 and part of these activities are held by Instituto Camões. For the surprise, according to this article, the number of students taking exams in Portuguese as a modern language within the British education system has risen steadily. This study, although was based in a polycentric approach between Portugal and the United Kingdom, shows that Portuguese is spoken in many countries of Europe as a mobility language and because of it this language has gaining different values.
Bortolini, Garcez and Sclatter has an article which analyse how Portuguese speaking Uruguayan around the border with Brazil construct their ideology related to Portuguese and Spanish, two languages more used there during daily activities. The study was conducted among members of local diglossic community (Spanish-Portuguese) around a bilingual public school in Rivera. Spanish and Portuguese have different value and function depending from the domain where people are. There are people who see the coexistence of these two languages as a transitory process but others have a different ideology that emphasises the idea of permanent languages that are symbols of people's identities of the community.

Patel and Cavalcanti wrote an article about the coexistence between Portuguese and African languages in education in Mozambique. They put emphases on the language ideological debates about unity and diversity. The article starts from discussing the choice of Portuguese as the official language and the medium of instruction in a country where the majority of population does not speak it. This ideology was problematized and recently in Mozambique was adopted the use of Portuguese together with some African language as medium of instruction. This new political decision has divided the public opinion. From the one side, some see it as good because it works as medium of integration of those who do not speak Portuguese but from the other side, the others see this ideological decision as the beginning of lose of national unity. These ideas came up from a fieldwork done by Patel in a bilingual teacher education course at the Eduardo Mondlane University and in two centres for pre-service teacher education, called Institutes for Teachers Training. 
Carneiro's article discusses the situation of Portuguese in multilingual context of East-Timor. According to Carneiro at East-Timor there is language ideological debate going on. The problem of language legitimacy among different languages spoken there is another topic that he analyses on this article. Carneiro mentions that in EastTimor there are different autochthonous languages but only two languages are official (Tetun and Portuguese), apart from this English and Indonesian are used as working languages. The debate on Internet about a pilot project for the introduction of "mother tongues" in local schools is also mentioned here. This study was done through the collection of data from the census of 2004 and 2010 and it was increased by a participant observation made by Carneiro in 2010 during his fieldwork in East-Timor.

The book ends with an afterword written by Stroud. Stroud describes the importance of each study presented on this book centred on three coordinates: temporal, spatial or geographical and scalar. According to Stroud almost all chapters develop a critical approach to hegemonic ideologies of Portuguese from a truly post-structuralist, ethnographic involvement with the local and a development of a Bourdieu-inspired understanding of language (p. 225).

Finally, I cannot finish without give my positive appreciation to this book. The articles explain clearly the complexity of Portuguese language around the world including the everyday challenges that this language has to be used as official language in some countries and as language of diaspora in other countries. I recommend this book for all who are interested on questions of languages, mobility and post-colonial transformations. The book shows the challenge that Portuguese had in many countries after the end of colonial regime where in almost all the countries this language had to cohabit with local languages and it created a strong dispute on the linguistic market for the survive of Portuguese, including its expansion for other countries like the United Kingdom mentioned on this book. The geographical localization is something irrelevant, in almost all countries where Portuguese is spoken there is the same ideologically challenging concerned with the coexistence of this language with other languages sometimes the most spoken ones.

\section{Manuel Guissemo}

